\title{
Delay in Cancer Diagnosis During the Era of the Coronavirus Disease 2019 Pandemic Learning lessons
}

\author{
Mohammed H. Al-Azri
}

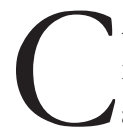
ANCER IS ONE Of THE LEADING CAUSES OF mortality worldwide and was responsible for an estimated 9.6 million deaths in 2018, with the majority (70\%) occurring in low- and middleincome countries (LMICs). ${ }^{1}$ Furthermore, cancer survival tends to be poor in LMICs, most likely due to delays in cancer diagnosis, limited access to resources and a lack of national cancer screening programmes. ${ }^{2}$ As such, the number of cancer-related deaths can be reduced if patients are diagnosed and treated early. ${ }^{1}$ Delay in cancer diagnosis can occur at any point along the diagnostic spectrum, from the first observation of symptoms to the start of treatment and are typically categorised within one of the three time intervals: patient, primary care and secondary care intervals [Figure 1]. ${ }^{3}$

In March 2020, the World Health Organization (WHO) declared that the coronavirus disease 2019 (COVID-19) virus had become a global health problem; accordingly, most countries developed specific policy responses to decrease the number of infections and slow the transmission of the virus, including the implementation of national lockdowns and social distancing guidelines. ${ }^{4}$ The intention behind these measures was to 'flatten the curve' of the infection and to minimise the impact of the pandemic on national healthcare services and resources. ${ }^{5}$ However, a recent study conducted in the UK predicted that the disruption of routine health services and other aspects of the COVID-19 pandemic would lead to a substantial increase in the frequency of avoidable deaths by $7.9-9.6 \%$ among patients with breast, colorectal, oesophageal and lung cancers as a result of diagnostic delays, resulting in a total of 59,204-63,229 additional lives lost in a year. ${ }^{6}$

In response to the pandemic, routine or nonurgent appointments in primary care settings were cancelled in many countries, including LMICs, and cancer screening services were suspended so as to limit gatherings of multiple individuals and decrease the risk of exposing patients and staff to possible sources of infection. ${ }^{7}$ Moreover, hospital resources were diverted to accommodate patients with severe illness due to COVID-19; as such, many essential cancer diagnostic procedures such as radiology and endoscopic procedures were suspended or continued operating solely in an extremely limited capacity. ${ }^{8}$ Elective surgeries for those already diagnosed with cancer were deferred indefinitely, while only urgent surgeries were permitted, often resulting in severe psychological distress to the affected patients and caregivers. ${ }^{9}$ Services in the primary care sector were restructured to implement mandatory COVID-19 triaging, screening, swab-taking and quarantine or isolation procedures, with staff training implemented to ensure the appropriate referral and management of symptomatic and asymptomatic patients. ${ }^{10}$ Although these measures were undoubtedly necessary, such changes have had a profound effect on existing essential cancer services, leading to further delays in cancer diagnosis and worsening patient outcomes, including their survival rate. ${ }^{11}$

In some countries, the rate of referral for potential cancer cases has decreased by $80 \%$ or more, even for patients in whom cancer is highly likely and who would normally be directed into urgent two-weekwait referral pathways. ${ }^{12}$ In April 2020, the number of urgent referrals of cancer patients by primary care physicians in Scotland and England decreased by more than $70 \%$ compared to the average rate over the preceding three years. ${ }^{13}$ Instead, the only way in which patients can currently present to doctors with possible cancer symptoms is through emergency departments. However, even emergency visits were found to have dropped by nearly 33\% in March 2020, compared to the previous year, in the UK; moreover, while certain types of cancer (e.g. lung and colorectal) can manifest at an early stage with alarming symptoms (i.e. coughing up blood or blood in the stool), which would trigger a visit to the emergency department, other types of cancer (e.g. breast and prostate) are less likely to be associated with such complications. ${ }^{10,13}$ As a result, researchers have calculated that approximately 2,000 fewer diagnoses of cancer are currently being made per week in the UK. ${ }^{13}$ Furthermore, it has been found that patients who are diagnosed with cancer 


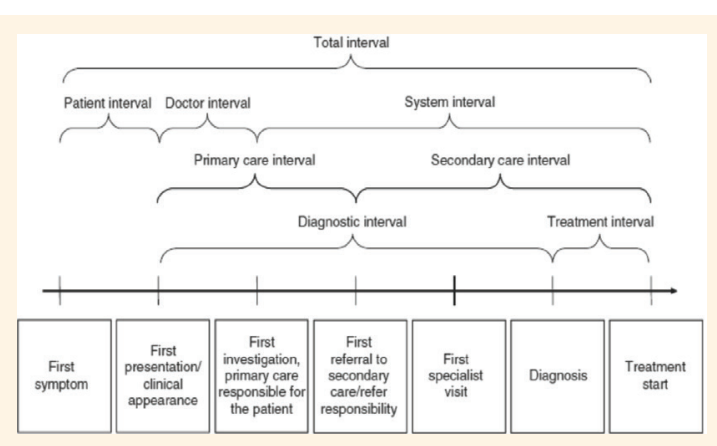

Figure 1: Diagram showing key time points and diagnostic intervals between observation of the first symptom of cancer until the start of treatment.

Reproduced from Coxon D, Campbell C, Walter FM, Scott SE, Neal RD Vedsted $P$, et al. The Aarhus statement on cancer diagnostic research: Turning recommendations into new survey instruments. ${ }^{3}$

after initially presenting to an emergency department demonstrate poorer outcomes and lower survival rates compared to those with other routes of presentation, such as primary care settings. ${ }^{14}$

Attitudes and help-seeking behaviours on the part of patients have also changed substantially during the COVID-19 pandemic in response to physical and social distancing measures introduced by politicians and healthcare authorities to slow or limit the transmission of infection. ${ }^{15}$ Many patients are reluctant to consult a doctor in primary care because of the anxiety over acquiring or transmitting the COVID-19 infection and concerns about wasting the doctor's time for non-COVID-19-related symptoms. ${ }^{16}$ In addition, some patients may be discouraged from seeking medical help as they believe that being diagnosed with cancer might place them at a higher risk of developing serious complications if they were subsequently infected by COVID-19. Unfortunately, this fear is justified given that COVID-19-related mortality appears to be higher among cancer patients compared to those without cancer ( $6 \%$ versus $2 \%$ ), likely due to immunocompromise resulting both from the disease itself as well as its various treatment modalities such as surgery, radiation and chemotherapy. ${ }^{17}$

Various measures have been implemented in order to limit the risk of transmission of COVID-19 while still delivering and facilitating health-related services. In many countries, face-to-face consultations with primary care doctors are being reserved for patients with urgent concerns, while consultations for non-urgent issues are being conducted virtually through online and telehealth technologies. ${ }^{18}$ However, not all patients in LMICs have the necessary access to, familiarity with or knowledge of such technologies to make appropriate use of telemedicine services. ${ }^{19}$ Indeed, even in developed countries, patients from low socioeconomic backgrounds are much less likely to arrange and utilise online telehealth consultations, further compounding the ongoing socioeconomic divide in delays in cancer diagnosis. ${ }^{20}$ Furthermore, the unavoidable drawbacks associated with virtual consultations can increase the chance of a missed cancer diagnosis as the result of the inability of the consulting doctor to conduct physical examinations. ${ }^{21}$

A substantial increase in the number of avoidable cancer deaths globally is, therefore, to be expected as a result of diagnostic delays due to the COVID-19 pandemic. Furthermore, it is anticipated that the health systems of many countries, particularly LMICs, will be severely strained in the coming months and possibly years due to the foreseeable influx of patients presenting with advanced-stage cancer as a result of current diagnostic delays. As such, the ongoing impact of this outbreak on cancer services requires careful forethought and analysis so that negative outcomes can be minimised as much as possible.

As the first anniversary of the official declaration of the COVID-19 global pandemic approached, healthcare authorities and policy-makers should consider taking certain steps to mitigate cancer delays and deal with the coming influx of patients presenting with advanced-stage cancer. First, the public should be reassured of their safety and the importance of seeking early medical help for possible cancer symptoms, even during the pandemic. Traditional and social media campaigns along with interviews with healthcare professionals and politicians should be conducted to reassure the public of their safety when attending healthcare facilities and to encourage participation in cancer screening programmes to help overcome potential barriers to medical help-seeking caused by the COVID-19 pandemic. . $^{15,22}$

Second, cancer diagnostic and treatment services such as surgery and endoscopy must be made accessible and available while adhering to strict infection prevention and control policies, for instance, by stressing the importance of hand hygiene, use of personal protective equipment, the implementation of aseptic 'no-touch' techniques for all invasive procedures and routine environmental cleaning and waste management as well as respiratory hygiene and cough etiquette. Third, the capacity of current cancer services and resources-including diagnostic procedures, radiology and elective surgeries-should be increased to meet the extra demand that will ensue from the growing backlog of undiagnosed and untreated cancer patients. Nonetheless, this will be a major challenge in many LMICs where national healthcare systems are already stretched to nearly full capacity under normal circumstances. ${ }^{2,20}$ 


\section{References}

1. World Health Organization. Cancer. From: www.who.int/ news-room/fact-sheets/detail/cancer Accessed: Jan 2021.

2. Shah SC, Kayamba V, Peek RM Jr, Heimburger D. Cancer control in low- and middle-income countries: Is it time to consider screening? J Glob Oncol 2019; 5:1-8. https://doi. org/10.1200/JGO.18.00200.

3. Coxon D, Campbell C, Walter FM, Scott SE, Neal RD, Vedsted P, et al. The Aarhus statement on cancer diagnostic research: Turning recommendations into new survey instruments. BMC Health Serv Res 2018; 18:677. https://doi.org/10.1186/s12913018-3476-0.

4. World Health Organization. WHO Director-General's opening remarks at the media briefing on COVID-19: 27 July 2020 From: www.who.int/dg/speeches/detail/who-director-generals-opening-remarks-at-the-media-briefing-on-covid-19---27july-2020 Accessed: Jan 2021

5. UK Government. COVID-19: Guidance for health professionals. From: www.gov.uk/government/collections/wuhan-novel-coro navirus Accessed: Jan 2021.

6. Maringe C, Spicer J, Morris M, Purushotham A, Nolte E, Sullivan R, et al. The impact of the COVID-19 pandemic on cancer deaths due to delays in diagnosis in England, UK: A national, population-based, modelling study. Lancet Oncol 2020; 21:1023-34. https://doi.org/10.1016/S1470-2045(20)303 88-0.

7. Chudasama YV, Gillies CL, Zaccardi F, Coles B, Davies MJ, Seidu S, et al. Impact of COVID-19 on routine care for chronic diseases: A global survey of views from healthcare professionals. Diabetes Metab Syndr 2020; 14:965-7. https://doi. org/10.1016/j.dsx.2020.06.042.

8. Cooley L, Linn JF. Developing countries can respond to COVID-19 in ways that are swift, at scale, and successful. From: www.brookings.edu/blog/future-development/2020/06/04/ developing-countries-can-respond-to-covid-19-in-ways-thatare-swift-at-scale-and-successful/ Accessed: Jan 2021.

9. Canadian Cancer Survivor Network. The devastating effect on cancer care of cancelling elective surgeries during the pandemic. From: https://survivornet.ca/news/the-devastatingeffect-on-cancer-care-of-cancelling-elective-surgeries-duringthe-pandemic/ Accessed: Jan 2021.

10. Lash RS, Bell JF, Reed SC, Poghosyan H, Rodgers J, Kim KK, et al. A systematic review of emergency department use among cancer patients. Cancer Nurs 2017; 40:135-44. https://doi. org/10.1097/NCC.0000000000000360.

11. Al-Azri MH. Delay in cancer diagnosis: Causes and possible solutions. Oman Med J 2016; 31:325-6. https://doi.org/10.5001/ omj.2016.65
12. Bodkin H. Cancer referrals down by 80 per cent in some areas as coronavirus fears keep patients from hospitals. From: www. telegraph.co.uk/news/2020/04/15/cancer-referrals-80-per-centareas-coronavirus-fears-keep-patients/ Accessed: Jan 2021.

13. Richards M, Anderson M, Carter P, Ebert BL, Mossialos E. The impact of the COVID-19 pandemic on cancer care. Nat Cancer 2020; 1:565-7. https://doi.org/10.1038/s43018-020-0074-y.

14. King-Okoye M, Arber A, Faithfull S. Routes to diagnosis for men with prostate cancer: Men's cultural beliefs about how changes to their bodies and symptoms influence help-seeking actions - A narrative review of the literature. Eur J Oncol Nurs 2017; 30:48-58. https://doi.org/10.1016/j.ejon.2017.06.005.

15. Kennedy M. U.K. Prime Minister tells Brits they must stay home, threatens fines. From: www.npr.org/sections/coronavirus-liveupdates/2020/03/23/820335870/u-k-prime-minister-tells-britsto-stay-home-threatens-fines Accessed: Jan 2021.

16. Dinmohamed AG, Visser O, Verhoeven RH, Louwman MW, van Nederveen FH, Willems SM, et al. Fewer cancer diagnoses during the COVID-19 epidemic in the Netherlands. Lancet Oncol 2020; 21:750-1. https://doi.org/10.1016/S1470-2045(20) 30265-5.

17. Tsamakis K, Gavriatopoulou M, Schizas D, Stravodimou A, Mougkou A, Tsiptsios D, et al. Oncology during the COVID-19 pandemic: Challenges, dilemmas and the psychosocial impact on cancer patients. Oncol Lett 2020; 20:441-7. https://doi. org/10.3892/ol.2020.11599.

18. Lynn Community Health Center. Health center to cancel some appointments, increase screening in response to coronavirus. From: www.lchcnet.org/health-center-cancel-some-appo intments-increase-screening-response-coronavirus Accessed: Jan 2021.

19. World Health Organization. E-health in low- and middleincome countries: Findings from the Center for Health Market Innovations. From: www.who.int/bulletin/volumes/9 0/5/11-099820/en/ Accessed: Jan 2021.

20. Rivera-Franco MM, Leon-Rodriguez E. Delays in breast cancer detection and treatment in developing countries. Breast Cancer (Auckl) 2018; 12:1178223417752677. https://doi.org/10.1177/1 178223417752677 .

21. Jones D, Neal RD, Duffy SR, Scott SE, Whitaker KL, Brain K. Impact of the COVID-19 pandemic on the symptomatic diagnosis of cancer: The view from primary care. Lancet Oncol 2020; 21:748-50. https://doi.org/10.1016/S1470-2045(20)30242-4.

22. Hamilton W, Walter FM, Rubin G, Neal RD. Improving early diagnosis of symptomatic cancer. Nat Rev Clin Oncol 2016; 13:740-9. https://doi.org/10.1038/nrclinonc.2016.109. 